\title{
Empirical Study on Public High School System in Vietnam: Post Doi Moi
}

\author{
Tran Duy Nam, PhD, Lecturer \\ Ha Thanh Viet, Associate Prof., Principal \\ Institute of Educational Managers Ho Chi Minh City, Vietnam
}

Doi: 10.19044/esj.2017.v13n31p92 URL:http://dx.doi.org/10.19044/esj.2017.v13n31p92

\begin{abstract}
The system of education in Vietnam is administered by the Ministry of Education and Training (MOET), and it is a broad system of state-run schools for students from about four years of age to high school age. The educational system comprises of five classes: kindergarten, primary, secondary, upper-optional (additionally alluded to as secondary school), and college level, with broadly managed exit and selection tests between each. The principal motivation behind this study is to analyze the connection between pre-secondary school factors, school condition, school structure, collective duty, scholarly optimism with the scholastic performance of the public high school students in Vietnam. SPSS analysis shows that only two variables can be a significant indicator of academic performance, that are school environment $(\mathrm{B}=-1.369, \mathrm{t}=51.356, \mathrm{p}<0.01)$ and pre-high school factor $(\mathrm{B}=-.384, \mathrm{t}=-13.947, \mathrm{p}<0.01)$ while school structure, collective responsibility, and academic optimism have found to be insignificant indicator of academic performance as compared to the other two variables in a multivariate context although, during the bivariate analysis, academic optimism had been found to be significantly related to academic performance. School environment was also found to have higher ' $\mathrm{B}$ ' value compared to pre-high school factor. Hence, this study suggests that among all the independent variables studied, school environment gave the most effective towards the academic performance of students in the public high school of Vietnam.
\end{abstract}

Keywords: Academic performance, public high school, pre-high school experience, school environment, school structure, collective responsibility, academic optimism, Vietnam, Doi Moi 


\section{Introduction}

In the twenty-first century, science and technology continue to develop and strengthen, forming a foundation for the development of a knowledge economy. Education is the foundation for scientific and technological development, human resource development, talent fostering, improving people's knowledge and meeting the requirements of the innovative development of modern society. In this context, Vietnam has to rapidly develop high-quality human resources, conduct research and apply specific technologies (information and communication technology, biotechnology, nanotechnology, electronics, automation, etc.) and new materials to create a foothold in the world technology market. Globalization and international integration is a collaborative process for development, but it is a competitive process in terms of protecting national interests, especially in developing countries like Viet Nam. International economic competition is becoming increasingly fierce and intense, wealthy countries are increasingly rich as a result of their competitive advantage in training high-quality human resources and in researching and developing advanced technology (Education for All, 2015).

The education system in Vietnam is administered by the Ministry of Education and Training (MOET), and it is a broad system of state-run schools for students from approximately four years of age to school age. The framework comprises of five classes: kindergarten, essential, auxiliary, upper-optional (likewise alluded to as secondary school), and college level, with broadly regulated exit and placement tests between each. Despite the fact that there is a developing number of tuition based schools and mostly privatized schools, these exist only in Hanoi and Ho Chi Minh City (HCMC), and students at these schools still speak to a particular minority of candidates to schools and colleges abroad (Education for All, 2015).

Among upper secondary schools, there are a few classes of schools important to U.S. school and college affirmations experts: worldwide schools, "specific" schools (additionally in some cases alluded to as "magnet" schools), and the customary secondary schools. While years prior it was just at the universal and particular schools that spotters could discover students with an abnormal state of English and the family bolsters important to think about abroad, this is not true anymore. English has turned into a compulsory subject in many schools, and as students start learning at more youthful ages, levels of English familiarity have expanded definitely. Global and concentrated secondary schools still send the most students to another country, a pattern straightforwardly identified with the gauge of students in participation. A huge number of students ponder in night and end of the week classes for the secondary school selection tests that could give them a place in Hanoi's Foreign Language Specialized School (FLSS) or Hanoi- 
Amsterdam School for the Gifted ("Hanoi-Ams" for short), however, just around 5 percent are picked every year. The individuals who make it in get an instruction with more qualified educators, more grounded and more unique educational programs, and a more extensive exhibit of an extracurricular exercises-every single pivotal segment of a decent training and factors that will seriously affect the subsequent stage of their training. A developing number of worldwide schools either educate altogether in English or are bilingual, however, these schools, for the most part, pull in the offspring of ostracizes and rich Vietnamese. The students who don't make it into these projects frequently wind up in specific companions inside the customary state-funded schools, or in private secondary schools, both of which are endeavors to address the developing interest for particular projects and quality instruction regardless of constrained assets (Education for All, 2015).

\section{Literature review}

\section{Pre-High School Factors on Academic Performance}

Higher levels of academic preparation and student motivation are known to closely align with student academic success (Kuh, 2005; Perna, 2006). It is evident that the concept of school "preparation" goes well beyond standard academic competencies such as strong study skills, reading comprehension, and high standardized test performance. It has even been demonstrated that early social influences, such as the culture of the student's particular neighborhood, deter students from attending school, even in the face of strong personal motivation (Stewart, 2007).

Students may also be more prepared to attend college and succeed if they have stored significant "social capital" through continuous, positive social and educational experiences during their formative years. For students of limited means, and first-generation students, a relative lack of social capital may leave them underprepared for interaction with teachers (Padgett, 2012).

It is noteworthy that some debate exists as to whether the povertyperformance correlation is, in fact, an over-generalization of more subtle phenomena. Some evidence exists to indicate that "academic resources" available to the student may be a better overall predictor of future educational success than other measures, even socioeconomic ones (Adelman, 1999). Adelman's study used a massive bank of data collected by the National Center for Education Statistics on the scheduled graduating class of 1982, from 10th grade in 1980 until age thirty in 1993. This longitudinal study performed least squares regression analysis on these data sources, which included records of the high school, to highlight the causes that contributed to high attrition rate among the high school students. 


\section{School Environment on Academic Performance}

The impacts of the school environment on student academic success have been studied at length. The majority of the literature examines the school environment in the context of academic and non-academic factors that influence the student while in school. Related to this, a study on college student academic performance can be a good source of guidance on this matter. Based on Astin's (1993) model, a large, longitudinal study examined data from over 200 institutions and 25,000 students in order to ascertain which dimension of the student learning experience hugely impacted on the results of the education. It was conducted across all institutional types, including large, research-intensive universities and small public colleges. Astin's study made a number of critical findings, but the most critical were that nearly any form of activity that better engages students in the college environment, commonly referred to as "time on task", contributes to student learning and development (Astin, 1993). Further, Astin found that several other factors correlated significantly with student success: teacher roles, extracurricular involvement, living arrangements, and peer groups, among others (Astin, 1993).

\section{School Structure on Academic Performance}

Schools have many trappings of bureaucracy; they are structures with hierarchy of power, specialization, formal and non-personal, laws and regulations, and a career ladder for advancement and success (Hoy and Miskel, 2012; Weber, 1947). Despite the fact that Weber (1947) contended that from an absolutely specialized perspective a bureaucratic organization is equipped for creating the best level of productivity, bureaucracies are most often stigmatized as rigid structures (Merton, 1957) that distort communication (Blau \& Scott, 1962), stifle innovation (Hage and Aiken, 1970), promote conformity (Gouldner, 1954), and alienate and exploit workers (Adler and Borys, 1996). However, contemporary studies of schools often neglect the organizational structure in favor of symbolic analyses of culture (Bolman and Deal, 2008; Schein, 2004), political inquiries of power and policy (Flyvbjerg, 1998; Elmore, 2002), and studies of the accommodation of individuals (Duckworth et al., 2009; Seligman, 2011). Therefore, this inquiry intends to refocus on the role of organizational structure and to examine how it promotes the success of scholastic achievement for all students. In one of the few recent studies of school structure, McGuigan and Hoy (2006) demonstrated that structure had an indirect influence on the success of scholastic achievement of students regardless of their socioeconomic background. In their study, the structure was a key variable in shaping a culture of academic optimism. 


\section{Collective responsibility on Academic Performance}

The Aggregate obligation is an arrangement of school standards that mirror instructors' readiness to assume liability for the learning of their students (Lee and Smith, 1996). Lee and Smith were the primary specialists who conceptualized aggregate obligation regarding understudy learning and analyzed its impact on scholastic accomplishment. They postulated that when the teacher as a group believed that their efforts were crucial in the learning process (high collective responsibility), then there would be increased teacher effort and higher student achievement. Lee and Smith confirmed their prediction that collective responsibility was positively related to achievement while controlling for SES. When the group assumes responsibility for all students regardless of previous achievement or social background, learning will likely be more equitably distributed among all students in the school.

\section{Academic optimism on Academic Performance}

Academic optimism is a collective property of schools that describes school culture in terms of the emphasis on academic achievement, the degree to which the teacher trusts parents and students, and the extent of collective efficacy of the teacher. Previous research (Forsyth et al., 2011; Hoy et al., 2006 a,b; Smith and Hoy, 2007) has demonstrated that these three constructs work together in a unifying fashion to form a more general construct that has been labeled academic optimism. Aggregate adequacy is the intellectual face of scholastic positive thinking-the reasoning and trusting side; instructor confide in students and guardians is the full of feeling and passionate side of the development; and scholarly accentuation is the behavioral face, that is, the institution of the subjective and emotional vigorously. The author shifts quickly to the three segments of scholarly positive thinking, each of which has been exhibited to be identified with understudy accomplishment paying little mind to the SES of the school.

\section{Research Framework}

From the extant literature review, below is the research framework which shows the hypothesized model for the current study. 


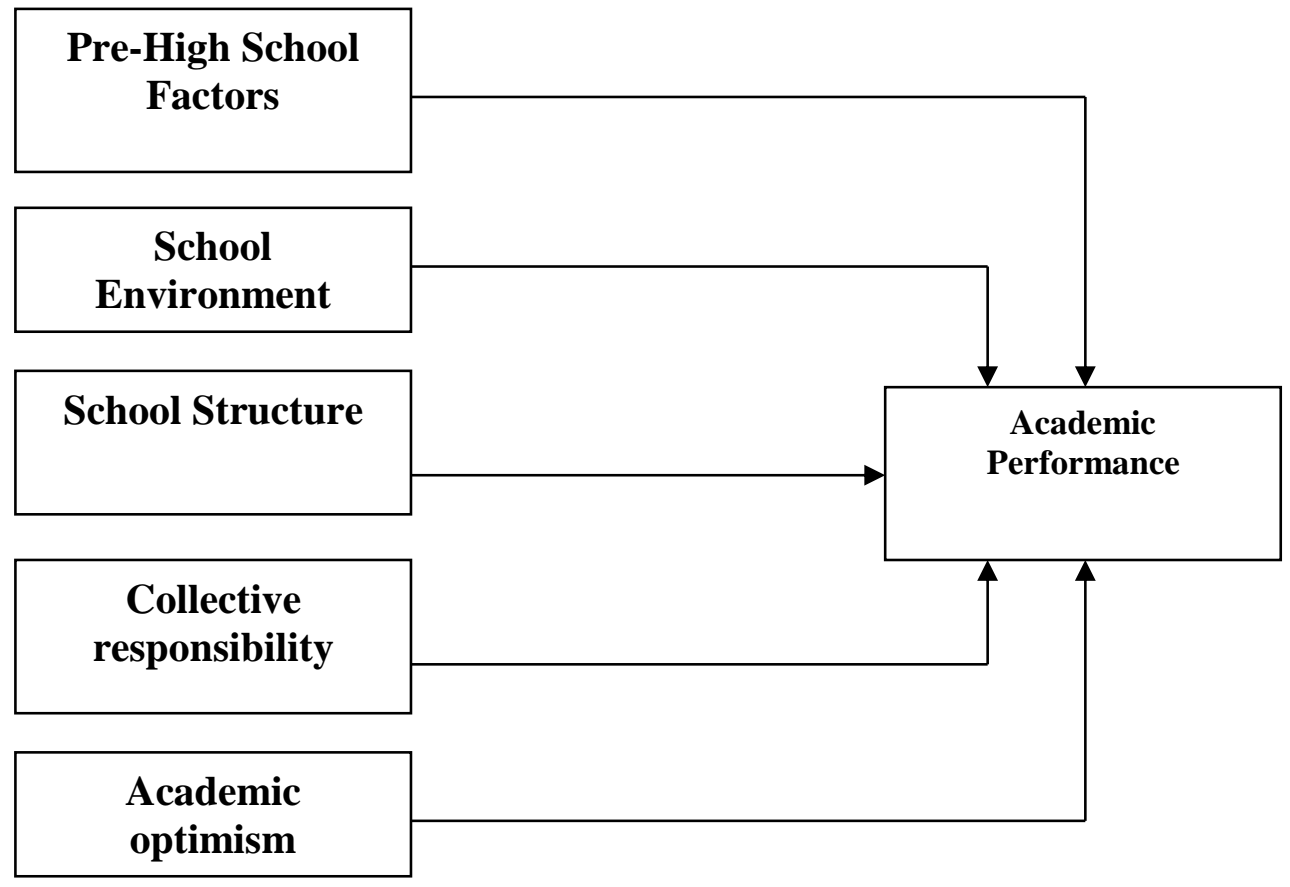

Figure 1.1: Research Framework

\section{Hypotheses of the Study}

In order to answer the research questions of this study, the following research hypotheses were developed based on the given research framework (see Figure 1.1). The main purpose is to examine the relationship between pre-high school factors, school environment, school structure, collective responsibility, academic optimism with the academic performance of the public high school students in Vietnam. Hence, based on the research framework of this study as seen in Figure 1.1, the followings are the research hypotheses of the study.

H1: There is a significant relationship between pre-high school factors and the academic performance of public high school students $\mathrm{H} 2$ : There is a significant relationship between school environment and the academic performance of public high school students

H3: There is a significant relationship between school structure and the academic performance of public high school students

H4: There is a significant relationship between collective responsibility and the academic performance of public high school students 
H5: There is a significant relationship between academic optimism and the academic performance of public high school students

\section{Methods and techniques of the study}

The main objectives of the study are to ascertain the relationship that may exist between pre-high school factors, school environment, school structure, collective responsibility, academic optimism with the academic performance of the public high school students in Ho Chi Minh, Vietnam. The major data were mainly collected through survey questionnaires between the months of January - June 2017. The resources surveyed as part of this study were identified as a result of an extensive Internet search utilizing available meta search engines. This search uncovered numerous journal articles, dissertations and statistical studies addressing student achievement.

Research is defined as the "pursuit of the truth" (Hair et al., $2007 \mathrm{pg}$. 4). A business research then again is characterized by Sekaran (2005) as "composed, efficient, information based, basic, objective, logical request or study concerning a particular issue, attempted with the motivation behind discovering answers or answers for it". According to Hair et al. (2007), a business research contains several key elements comprising of which a business research can be broad, formal, informal, and replicable and the benefits should outweigh the costs.

In this study, quantitative research was utilized based on Williams and Monge's (2001) explanation. This approach is suitable when three conditions are presents; measurement is relevant and possible, statistical generalizations may be applicable to the problem, and when probabilities or hypothesis tests are thought to be useful.

\section{Sampling and Population}

The process of sampling is operationalized as "the way toward choosing an adequate number of components from the populace with the goal that an investigation of the specimen and a comprehension of its properties or qualities would make it feasible for the speculation of such properties or attributes to the populace components" (Sekaran, 2005). Therefore, a sample simply means a subset of a population (Sekaran, 2005; Hair et al, 2007). Thus, the unit of analysis in this study is the students who are currently studying at the public high schools in Ho Chi Minh, Vietnam which is estimated to be 880,000 public high school students in 2017 (www.moet.gov.vn). 


\section{Sampling method}

A probability sampling method is employed for this research. Usually, the results from a probability sampling can be generalized to the entire population of a specified level of confidence. Thus in order to collect the samples, this study utilized the systematic random sampling, which represented one of the most commonly used methods when a generalization is of concern. It is a method involves the process of randomly selecting an initial starting point on a list and thereafter every $\mathrm{K}^{\text {th }}$ element in the sampling frame is selected (Hair et al., 2007).

\section{Sample size}

Roscoe (1975) had also suggested that generally, a sample size should fall between 30 to 500 samples. In most researches and about multiple regression analyses, Roscoe (1975) had likewise proposed that the example size ought to be a few times (ideal ten times or more) as extensive as the quantity of factor in the investigation. What's more, Hair et al. (2007) had additionally suggested a base specimen size of 30 or bigger is essential in any given research.

Thus, this research fulfills the rule of thumb as proposed by Roscoe (1975) by selecting randomly approximately 150 respondents out of 880,000 public high school students in Vietnam.

\section{Instruments of the Study}

The questionnaire for this study contained 54 items and was filled out by the sample students. This instrument in Part A sought the following information on the background of the students which among all comprised of the gender, age, parents' occupation and education, availability of resources at home, assistance at home and time spent on learning activities after school, type of school attended and reason for attending such school as well as their level of performance as perceived. As for Part B, the questionnaire contained questions related to the variables understudy which is the academic performance, pre-high school factor, school environment; school structure, collective responsibility and the academic optimism (see Appendix A).

\section{Data Gathering Procedure}

All participants (school heads, teachers, and students) were asked to complete a survey questionnaire which includes demographic data. In order to collect data for this study, a survey method was employed in which it involved the collection of numerical data using a structured questionnaire that was used to collect primary data from the samples. A questionnaire is a 
pre-formulated written set of questions to which respondents record their answers, usually within closely defined alternatives (Sekaran, 2005).

Before mailing took place, an effort was made to contact the teacherin-charge in each of the schools either through visitations, mails or through telephone calls in order to explain the purpose of the research. When approval was received, each questionnaire was placed in an envelope enclosed with a cover letter along with a stamped return addressed envelope so that it will be convenient for the respondent to post it once it is completed. The cover letter contained an explanation of the purpose of the research, which is solely for academic research and an assurance that only the researcher shall have access into the responses given by the students.

\section{Data Analysis}

The data gathered from the survey questionnaires were analyzed by using quantitative research method software, Statistical Package of Social Science (SPSS) version 22.0. This study employed descriptive statistics such as computation of frequencies, means, standard deviations, and percentages to analyze and interpret the responses. The robust statistical analysis tool, SPSS was used to perform the inferential analysis of the data sets.

Every single gathered response was legitimately analyzed before they were coded into SPSS adaptation 22.0. This information screening process was done to guarantee that polls that were acquired were proper for the study regarding culmination or missing reactions. The Introductory investigation had additionally been directed keeping in mind the end goal to test the ordinariness of information. Typicality essentially implies how much the dispersion of the specimen information compares to an ordinary conveyance. This brought about the score on the factors accumulated around the mean in a symmetrical example of ringer formed or typical bend (Hair et al., 2006).

Once this is done, the data were analyzed using two approaches. The first approach involved using descriptive statistical analysis in order to determine the means, modes, and the standard deviations to measure the dispersions. Thus, the descriptive statistics were used in order to convey the essential characteristics of the collected data (Sekaran \& Bougie, 2009). The second approach used the inferential study for testing the hypotheses. This approach was employed to test the hypotheses using statistical tests, which can help to determine whether the proposed hypotheses can be confirmed by empirical evidence (Hair et al. 2007). In order to do this correlations as well as the regression analyses were carried out to explore the relationships between the independent variables with the dependent variable of this study. 


\section{Descriptive analysis}

In order to learn more and to describe the characteristics of the variables of interest, a descriptive study was carried out. In other words, a descriptive study will promote ideas for further research which will then assist in making simple decisions for many situations in a quantitative manner (Sekaran \& Bougie, 2009).

\section{Correlation analysis}

Fundamentally statistical tests will give the learning on whether there is a measurable affiliation that may exist between the factors under study. This can be resolved through connection investigation on the connection between the factors that are under study. The Pearson connection framework gives the qualities, bearing and criticalness of the bivariate relationship among every one of the factors that are measured utilizing the interim level (Sekaran and Bougie, 2009). Through the connection coefficients, the qualities and headings of the relationship can be known with +1.0 demonstrates an immaculate positive connection while - 1.0 demonstrates that there is a flawless negative connection. Consequently the positive $(+)$ and the negative (-) sign just demonstrates the heading of the connection between two factors (Johnson and Kuby, 2012).

In adopting the conventionally accepted standard of confidence level of 95 percent, the level of significance in this study was $p<0.05$ which indicated that at least 95 times out of 100 that the estimation will reflect true population characteristics with only 5 percent chance that the result will be wrong (Sekaran \& Bougie, 2009). Judging from this benchmark, this study can conclude that relationship between the variables exist when the significance level is at $\mathrm{p}<0.05$. In other words, there is insufficient evidence to accept the null hypothesis that no significant relationship exists.

\section{Regression analysis}

With a specific end goal to test the hypothesis for this study, regression analysis was connected. With a specific end goal to test each of the speculations, straightforward direct relapse $(\mathrm{Y}=\beta 0+\beta 1 \mathrm{X} 1+\varepsilon)$ was utilized while various relapses were utilized as a part of a request to decide the character of the connection between the autonomous factors and the needy variable. At the end of the day, it will uncover the relative significance of each of the autonomous factors (Sekaran and Bougie, 2009). Different relapse is communicated as in the accompanying condition:

Where:

$$
\mathrm{Y}=\beta_{0+} \beta_{1} \mathrm{X}_{1}+\beta_{2} \mathrm{X}_{2}+\ldots \ldots \ldots \ldots+\beta_{\mathrm{n}} \mathrm{Xn}+\varepsilon
$$

$\beta_{0}=\mathrm{a}$ constant, the value of $\mathrm{Y}$ when all $\mathrm{X}$ values are zero. 
$\beta i=$ the slope of the regression surface or response surface. The $\beta$ represents the regression coefficient associated with each $\mathrm{X} i$.

$\varepsilon=$ an error term, normally distributed about a mean of 0 . It is assumed to be $=0$ for the purpose of computation.

Through multiple regression, Hair et al. (2007) expounded that a researcher will be able to know whether relationship exists between the independent variables with the dependent variable, the strengths of the relations if does exist, the direction of the relationship that is whether it is positive or negative and finally how these existed relationship can be described in the best possible way.

\section{Hypotheses testing \& findings}

H1: There is a significant relationship between pre-high school factors and the academic performance of public high school students.

Table 1.1 describes the correlation matrix between academic performance and pre-high school. It is found that the correlation matrix (r) is 0.929 and significant value (p) is less than 0.01 . Hence it is concluded that there is a significant relationship between pre-high school factors and the academic performance of international public high school students. According to Davis (1971), this relationship is strong when the ' $r$ ' was ranged from 0.50 to 0.69 . Thus, the result supports hypothesis $\mathrm{H} 1$ that there a significant relationship between pre-high school factors and the academic performance of international public high school students.

Table 1.1 Pre-high school factors and the academic performance

\begin{tabular}{ccc}
\hline & academic performance (r) & Sig. \\
\hline Pre-high school factors & 0.929 & 0.000 \\
\hline
\end{tabular}

H2: There is a significant relationship between school environment and the academic performance of public high school students.

Table 1.2 describes the correlation matrix between academic performance and school environment. It is found that the correlation matrix (r) is 0.992 and significant value (p) is less than 0.01 . Hence it is concluded that there is a significant relationship between school environment and the academic performance of public high school students. Thus, the result supports hypothesis $\mathrm{H} 2$ that there a significant relationship between school environment and the academic performance of international public high school students.

Table 1.2 school environment and the academic performance

\begin{tabular}{ccc}
\hline & academic performance (r) & Sig. \\
\hline school environment & 0.992 & 0.000 \\
\hline
\end{tabular}

H3: There is a significant relationship between school structure and the academic performance of public high school students. 
Table 1.3 describes the correlation matrix between academic performance and school structure. It is found that the correlation matrix ( $r)$ is 0.28 and significant value $(\mathrm{p})$ is more than 0.01 . Hence it is concluded that there is no significant relationship between school structure and the academic performance of public high school students. Thus H3 is not supported.

Table 1.3 school structure and the academic performance

\begin{tabular}{ccc}
\hline & academic performance (r) & Sig. \\
\hline school structure & 0.28 & 0.781 \\
\hline
\end{tabular}

H4: There is a significant relationship between collective responsibility and the academic performance of public high school students.

Table 1.4 describes the correlation matrix between academic performance and collective responsibility. It is found that the correlation matrix (r) is 0.117 and significant value (p) is more than 0.01 . Hence it is concluded that there is no significant relationship between collective responsibility and the academic performance of public high school students. Thus H4 is not supported.

Table 1.4 collective responsibility and the academic performance academic performance (r)

collective responsibility 0.117

Sig. 0.248

H5: There is a significant relationship between academic optimism and the academic performance of public high school students.

Table 1.5 describes the correlation matrix between academic performance and academic optimism. It is found that the correlation matrix (r) is 0.617 and significant value (p) is less than 0.01 . Hence it is concluded that there is a significant relationship between academic optimism and the academic performance of public high school students. Thus, the result supports hypothesis H5 that there a significant relationship between academic optimism and the academic performance of public high school students.

Table 1.5 academic optimism and the academic performance

\begin{tabular}{ccc}
\hline & academic performance $(\mathbf{r})$ & Sig. \\
\hline academic optimism & 0.617 & 0.000 \\
\hline
\end{tabular}

The individual correlations between the independent variables and the dependent variable will collapse into multiple $\mathrm{r}$ (multiple correlation coefficient). The square of multiple $r$ is known as R-squared (R2) which reflects the amount of variance explained in the dependent variable by the independent variables (Sekaran \& Bougie, 2009). Thus this testing would allow us to know which among the five variables (pre-high school factors, school environment, school structure, collective responsibility and academic optimism) would have a more important effect on the academic performance 
of the public high school students. The result of the integration can be seen from Table 1.6

Table 1.6 Effect of pre-high school factors, school environment, school structure, collective responsibility and academic optimism on academic performance

\begin{tabular}{|c|c|c|c|c|c|c|c|}
\hline \multirow[t]{2}{*}{ Model } & \multicolumn{2}{|c|}{ Coefficients } & \multirow{2}{*}{\begin{tabular}{|c} 
Coefficients \\
Beta
\end{tabular}} & \multirow[t]{2}{*}{$\mathrm{t}$} & \multirow[t]{2}{*}{ Sig. } & \multicolumn{2}{|c|}{$\begin{array}{c}95.0 \% \\
\text { Confidence } \\
\text { Interval for B }\end{array}$} \\
\hline & B & $\begin{array}{l}\text { Std. } \\
\text { Error }\end{array}$ & & & & $\begin{array}{l}\text { Lower } \\
\text { Bound }\end{array}$ & $\begin{array}{l}\text { Upper } \\
\text { Bound }\end{array}$ \\
\hline (Constant) & .086 & .038 & & 2.237 & .028 & .010 & .163 \\
\hline SCHOOL_ENVIRONMENT & 1.324 & .026 & -1.369 & 51.356 & .000 & 1.273 & $\mathbf{1 . 3 7 5}$ \\
\hline PRE_SCHOOLEXP & -.329 & .024 & -.384 & $\overline{9}$ & .000 & -.376 & -.283 \\
\hline COLLECTIVE_RESP & .000 & .004 & .001 & .093 & .926 & -.008 & .008 \\
\hline SCHOOL_STRUC & -.005 & .004 & -.011 & -1.255 & .212 & -.012 & .003 \\
\hline ACA_OPTIMISM & -.011 & .010 & -.010 & -1.086 & .280 & -.031 & .009 \\
\hline \multicolumn{8}{|c|}{$R^{2}=0.995$} \\
\hline \multicolumn{8}{|c|}{$F=3985.238$} \\
\hline \multicolumn{8}{|c|}{ Sig. $=0.000$} \\
\hline
\end{tabular}

a. Dependent Variable: ACAD_PERF

Thus with the purpose of determining the percentage of variance in the dependent variable which was explained by the variation associated with all the independent variables, reference to the R-squared (R2) was made. It is also known as the measure of goodness of fit (Hair et al., 2007). Thus, when the value of $\mathrm{R} 2$ is near to 0 , it shows that most of the variation cannot be explained by the regression model. Conversely, when the value R2 is near to 1 , then the variation in the dependent variable can be explained by the regression model (Sekaran \& Bougie, 2009).

Consequently, pre-high school factors, school environment, school structure, collective responsibility and academic optimism were found to give a high impact to academic performance for 50.9 percent $\left(\mathrm{R}^{2}=0.995\right.$, $\mathrm{F}=3985.238, \mathrm{p}<0.01$ ). In order to determine which among the three independent variables plays an important role in influencing the dependent variable, reference is made to the regression coefficients. In view of the similarity of measurement scaled utilized in this study, the standardized regression coefficient Beta is used as suggested by Hair et al. (2006).

Inspection of Table 1.6 however shows that only two variables can be a significant indicator of academic performance that are school environment a $(B=-1.369, t=51.356, p<0.01)$ and pre-high school factor $(B=-.384, t=-$ 13.947, $\mathrm{p}<0.01$ ) while school structure, collective responsibility, and academic optimism have found to be insignificant indicator to academic performance as compared to the other two variables in a multivariate context 
although, during the bivariate analysis, academic optimism had been found to be significantly related to academic performance (see Table 1.7). School environment was also found to have higher ' $\mathrm{B}$ ' value compared to pre-high school factor. Hence, this study suggests that among all the independent variables studied, school environment gave the most effective towards the academic performance of students in the international public high school.

Table 1.7 Summary of hypotheses testing

\begin{tabular}{|c|c|c|}
\hline Hypotheses & Explanation & Result \\
\hline H1 & $\begin{array}{c}\text { There is a significant relationship between pre-high } \\
\text { school factors and the academic performance of public } \\
\text { high school students }\end{array}$ & Supported \\
\hline H2 & $\begin{array}{c}\text { There is a significant relationship between school } \\
\text { environment and the academic performance of public } \\
\text { high school students }\end{array}$ & Supported \\
\hline H3 & $\begin{array}{c}\text { There is a significant relationship between school } \\
\text { structure and the academic performance of public high } \\
\text { school students }\end{array}$ & Not Supported \\
\hline H4 & $\begin{array}{c}\text { There is a significant relationship between collective } \\
\text { responsibility and the academic performance of public } \\
\text { high school students }\end{array}$ & Not Supported \\
\hline H5 & $\begin{array}{c}\text { There is a significant relationship between academic } \\
\text { optimism and the academic performance of public high } \\
\text { school students }\end{array}$ & Supported \\
\hline
\end{tabular}

\section{Discussions on Findings}

Majority of the students obtained a score of 91 marks and above which comprised of $55 \%$.

The largest age group of the respondents was made up of those ranging from the age of 18 years old (52\%) while the smallest group comprised of those from the age of 16 years old $(8 \%)$.

The survey also found that the majority of the respondents father has an education ranging from the most in high school (45\%), university (38\%), followed by middle school (13\%) and informal education (4\%). As for the mother of the respondents, majority of them has a high school education (28\%) while a total of $26 \%$ of the students' mother had a university education. Some of them had middle school (17\%) followed by informal education $(22 \%)$ and elementary school $(5 \%)$ while only $2 \%$ of them have had no education.

As for the working background of the respondents' parents, majority of the parents of the students either work as non-professional private employment $(72 \%$ for the father of the students and $18 \%$ for their mothers) or being a self-employed at the rate of $23 \%$ (fathers) and $31 \%$ (mothers).

The findings also suggested that most of the respondents came from a private school at the lower level before they attended the private high school 
which accounted for $66 \%$ of the respondents and at the same time most of the students $(68 \%)$ have never repeat their grade.

The findings also revealed that more than half $(56 \%)$ of the respondents had chosen the school of their study based on the recommendation by the people that they knew who had also studied in the same school. The other reason of their choice of studying at the chosen of private school was due to they felt the teachers at the other school did not help them much (14\%) while a total of $10 \%$ of the respondents believe that their chosen school is known for higher performance on the national exam.

The level of education among the respondents' shows that majority (more than 50 percent) of them received tertiary education with those having first-degree forms the largest number (approximately 31 percent followed by those with diploma holders of around 21 percent). The finding was in contrast with the report from Census of Establishments and Enterprises, 2005 in which it was reported that majority of the employees working in the service sector SMEs possessed only SPM and below (a total of 72 percent ) which forms the largest group (Aris, 2007).

The findings of this study suggested that there exist significant relationships between pre-high school factors, school environment, and academic optimism and the academic performance among the students at the private high school.

Assessment through a multivariate analysis however shows that only two variables can be a significant indicator to academic performance, that are school environment a $(\mathrm{B}=-1.369, \mathrm{t}=51.356, \mathrm{p}<0.01)$ and pre-high school factor $(\mathrm{B}=-.384, \mathrm{t}=-13.947, \mathrm{p}<0.01)$ while school structure, collective responsibility and academic optimism have found to be insignificant indicator to academic performance as compared to the other two variables in a multivariate context although during the bivariate analysis, academic optimism had been found to be significantly related to academic performance.

School environment was also found to have higher ' $\mathrm{B}$ ' value compared to pre-high school factor. Hence, this study suggests that among all the independent variables studied, school environment gave the most effect towards academic performance of students in the private high school.

\section{Conclusion}

As a major aspect of the rebuilding of the education system and framework since Doi Moi or Renovation in 1989, the administration of Vietnam has executed a few change alternatives. These incorporate the change of some open organizations into open ones, fortifying the foundation of individuals' and group instructive establishments and allowing the foundation of open foundations. Since the move from a midway arranged 
economy to a market economy is extremely late, it isn't amazing that statefunded schools are moderately uncommon in Vietnam.

Vietnamese educational policy makers and managers need to understand that the human factor-teaching staff and educational managersplays a decisive role in improving the academic performance of students in general. Therefore, it is necessary for Vietnam to overcome weaknesses in pre-service and in-service training, deployment, organization and utilization of teachers. There seems to be a need to develop a pool of teaching staff of sufficient numbers, organized in an appropriate structure, and that meets the moral and professional requirements of the education renovation. At the same time, it is important to support educational managers with increased professionalism and standardized management capacities and qualifications.

One of the unequivocal goals of the Vietnamese government is that each kid in Vietnam ought to select in school. Despite the fact that larger part of them do, it is vital to discover approaches to urge the staying to enlist particularly among those originating from poorer families, families with generally uneducated guardians or potentially low wages are more averse to select their kids. This proposes a methodology whereby grants or vouchers are built up that would enable youngsters from low-salary families to select at a decreased cost (or no cost by any stretch of the imagination). A noteworthy issue with such a plan is, to the point that salary is hard to watch, so families with generally high salaries will endeavor to get a similar help, and it will be hard to keep this. In particular, kids whose guardians, particularly their moms, have low levels of training ought to be qualified for a grant or voucher conspire. Focusing on the offspring of guardians with low training is contended for in a progression of papers breaking down the determinants of kid work in various nations (Grootaert, 1997; Cartwright and Patrinos, 1997; Sakellariou and Lall, 1997). They contend that endowments ought to be given specifically to poor families with low parental instruction, who are inclined to having working youngsters, so they may stand to send their kids to class.

The influence of factor like enabling school structure on student achievement, the results were consistent with the current study; enabling structure worked through academic optimism to foster higher levels of achievement (McGuigan and Hoy, 2006). Not surprisingly, the way a school is organized can have positive or negative effects on teachers and students. Enabling structures capture teacher beliefs about how well the school is organized to support them and their students in general and teaching and learning in particular. The research findings here suggest that when teachers view the principal and structures as helpful and positive it facilitates a culture that emphasizes trust, efficacy, and academics, that is, a culture of academic optimism. Such a culture motivates teachers and students to set realistic 
goals, which when embraced guide behavior, encourage strong effort, promote persistence, and provide resilience in the face of difficulties (Forsyth et al., 2011; Hoy, 2012). Academic optimism in a school also prompts cooperation among students, parents, and teachers because of the pervasive relational trust that exists in such schools (Bryk and Schneider, 2002).

It should not be surprising that academic optimism can also affect academic achievement. The concept is a rich one that brings together and synthesizes three important ingredients of success: efficacy, trust, and academic emphasis. Experiencing achievement, modeling success, also, helping educators put stock in them are successful approaches to advance aggregate adequacy (Goddard et al., 2004). Staff confides in students and guardians is basic in building helpful and powerful endeavors and relations amongst guardians and students (Bryk and Schneider, 2002; Forsyth et al., 2011). An accentuation on scholastics guides activity in ways that prompt scholarly achievement.

\section{References:}

1. Adelman, C. (1999). Answers in the Tool Box: Academic Intensity, Attendance Patterns, and Bachelor's Degree Attainment. Washington, DC: Office of Education Research and Improvement, U.S. Department of Education.

2. Babbie, E. (2004). The practice of social research (10th ed.). Belmont, CA: Wadsworth

3. Bray, M (1996b). Privatization of Secondary Education: Issues and Policy Implications. Paris: UNESCO/IIEP

4. Bryk, A.S and Schneider, B.L. (2002), Trust in Schools: A Core Resource for Improvement, Russell Sage Foundation Publications, New York, NY.

5. DDS Research, Inc. (2004). Sampling error in survey research. Researcher's Resource Center. White Papers Library. Retrieved August 8, 2014, from http://www.dssresearch.com/toolkit.resource/papers.

6. Dillman, D. A. (2000). Mail and internet surveys: The tailored design method. New York: John Wiley \& Sons, Inc.

7. Dinavo, J. (1995). Privatization in Developing Countries: Its Impact on Economic Development and Democracy. London: Praeger Publishers

8. Duckworth, A.L., Quinn, P.D. and Seligman, M.E.P. (2009), "Positive predictors of teacher effectiveness", The Journal of Positive Psychology, Vol. 4 No. 64, pp. 540-7.

9. Education for All 2015 National Review Report: Viet Nam. 
10. Flyvbjerg, B. (1998), Rationality and Power: Democracy in Practice, University of Chicago Press, Chicago, IL.

11. Goddard, R.D., Hoy, W.K. and Woolfolk Hoy, A. (2000), "Collective teacher efficacy: its meaning, measure, and impact on student achievement", American Educational Research Journal, Vol. 37 No. 23, pp. 479-507.

12. Hair, J.F., Money, A.H., Samouel, P., \& Page, M. (2007). Research method for business. New Jersey: John Wiley \& Sons Limited.

13. Healey, J. (2005). Statistic-A Tool For Social Research (7th Ed). USA: Thomson Wadsworth.

14. Jimenez, E; Lockheed, M. (1995). Public and public secondary education in developing countries: a comparative study. Washington D.C.: The World Bank.

15. Johnson, R., \& Kuby, P. (2012). Elementary statistics. (11th ed.). US: Brooks/Cole Cengage Learning.

16. Jun, A. \& Colyar, J. (2002). Parental Guidance Suggested: Family Involvement in College Preparatory Programs. In W.G. Tierney \& L.S. Hagedorn, (Eds.), Increasing Access to College.

17. Kitaev, I (1999). Public education in Sub Saharan Africa: A re-study of hypothesis and concepts related to its development and finance. Paris: UNESCO/IIEP.

18. Kuh, G. and Pike, G. (2005). First-and Second-Generation College Students: A Comparison of Their Engagement and Intellectual Development. The Journal of Higher Education, 76(3), 276-300

19. Kumar, R. (1996). Research methodology: a step-by step guide for beginners. Melbourne: Longman Australia.

20. Leedy, P. D., \& Ormrod, J. E. (2001). Practical research: Planning and design. (7th ed.). Upper Saddle River, NJ: Merrill Prentice Hall.

21. Lewin, K. and Caillods, F. (2001). Financing secondary education in developing countries: strategies for sustainable growth. UNESCO/ IIEP

22. Linder, R. L., Murphy, T. H., \& Briers, G. E. (2001). The handling nonresponse in agricultural education. Papers presented at the 28th Annual National Agricultural Education Research Conference (pp. $233-245)$.

23. LoGerfo, L.F. and Goddard, R.D. (2008), "Defining, measuring, and validating teacher and collective responsibility", in Hoy, W.K. and DiPaola, M.F. (Eds), Improving Schools: Studies in Leadership and Culture, Information Age, Charlotte, NC, pp. 73-97.

24. Matthews, J. (2002, Oct. 6). Public school facing increased pressure to disclose information. The Star Ledger, 10, 7. 
25. McGuigan, L. and Hoy, W.K (2006), "Principal leadership: creating a culture of academic optimism to improve achievement for all students", Leadership and Policy in Schools, Vol. 5 No. 3, pp. 20329.

26. Michaiel, G. et. Al. (1999). Preliminary Assessment of Inputs and Processes Affecting the Educational Achievement of Grade 8 Pupils. National Organization of Studys, Ministry of Education, Ethiopia.

27. Pace, J. (2007). Understanding Authority in Classrooms: A Review of Theory, Ideology, and Research. Review of Educational Research. 77(1), 4-27.

28. Padgett, R. (2012). First-Generation Undergraduate Students and the Impacts of the First Year of College: Additional Evidence. Journal of College Student Development, 53(2), 243-266.

29. Pascarella, E. and Terenzini, P. (2005). How College Affects Students: A Third Decade of Research, Jossey-Bass, 2005

30. Pearl, D. K., \& Fairley, D. (1985). Testing for the potential for nonresponse bias in sample surveys. Public Opinion Quarterly, 49, 553-560.

31. Perna, L. W. (2006). Studying college choice: A proposed conceptual model. In J. C. Smart (Ed.), Higher education: Handbook of theory and research, Vol. XXI (pp. 91-157). New York: Springer.

32. Pham Minh Hac. (1995) The educational system of Vietnam. In Higher Education in Vietnam: Change and Response, ed. D. Sloper and L.T. Can. Institute of Southeast Asian Studies, Singapore.

33. Schein, E.H. (2004), Organizational Culture and Leadership, Wiley, San Francisco, CA.

34. Sekaran, U. (2005). Research Method for Business. (4th ed.). West Sussex UK: John Wiley \& Sons, Inc.

35. Sekaran, U., \& Bougie, R. (2009). Research methods for business. (5th ed.). West Sussex UK: John Wiley \& Sons, Inc.

36. Smith, P.A. and Hoy, W.K. (2007), "Academic optimism and student achievement in urban elementary schools", Journal of Educational Administration, Vol. 45 No. 5, pp. 556-68.

37. Stewart, E. (2007). The Effect of Neighborhood Context on the College Aspirations of African American Adolescents. American Educational Research Journal. 44(4), 896- 919

38. Tierney, W. G., Corwin, Z. B., \& Colyar, J. E. (2003). Preparing for College: Building Expectations, Changing Realities. Center for Higher Education Policy Analysis, Albany, NY: State University of New York Press. 


\title{
Appendix A: QUESTIONNAIRE
}

\section{SECTION A}

With your permission I would like to ask you some general as well as a few specific questions. Please know that your answers will be completely anonymous to guarantee a total confidentiality. Instructions: Please circle the answer for question 1 to 13 or filling out statements as appropriate

1. Indicate the range of your test scores for this year in this school

Less than 50 marks

50 to 60 marks

61 to 70 marks

71 to 80 marks

81 to 90 marks

91 to 100 marks

2. Sex:

3. Age

Female

Male

\author{
Below 15 years \\ 16-18 years \\ 19-21 years \\ 22-24 \\ Over 24 years
}

4. Father's education level

Elementary School

Middle School

High School

University

No education

Other, please specify

5. Mother's education level

Elementary School

Middle School

High School

University

No education

Other, please specify

6. Father's occupation
a) Civil servant
b) Military personnel
c) _ Merchant
d) Retailer
e) _L_Laborer/artisant/Fisherman/Blacksmith
f) Farmer
g) Driver 
h) Unemployed

i) __ Other, please specify

7. Mother's occupation
a) Civil servant
b) Military personnel
c) _ Merchant
d) Retailer
e) Housewife
f) _ Farmer
g) other, please specify

8. Before coming to this school, I attended:
a) public school
b) _ private school

9. Are you a repeater of this grade?
a) — YES
b) $\quad \mathrm{NO}$

10. Why did you and your family choose this school? (check all that applied)
a) This School is known for higher performance on the national exam
b) This School's location is more convenient for me
c) This School is assigned to me by school authorities
d) This School is smaller in school population
e) Classes in this school are smaller
f) _ Teachers at other school did not help me enough
g) _ People I knew were coming here
h) _ we heard that there are better teachers here
i) This School is safer
j) don't know
k) _ other, please specify

11. Do you have someone to assist you in your study after school?
a) __ust myself
b) _ my parents/relatives
c) _ my friends/classmates
d) I I pay a tutor (s)

12. How many hours per week do you study after school
a)_Less than $5 \mathrm{hrs}$ per week
b) 5-10hrs per week
c) 10-15hrs per week
d) 15-20hrs per week
e) 20-25hrs per week
f) 25-30hrs per week
g) More than 30hrs per week

13. By dividing the pupils of this class into three groups according to their academic performance, in which group you identify yourself?
a) among the best students
b) _ among the average students
c) _ among the lowest students 


\section{SECTION B}

Please read the following statement and circle/ shade the number that most accurately reflects your opinion on each statement based on these scales: Strongly Agree (6), Agree (5), Slightly Agree (4), Slightly Disagree (3) Disagree (2), and Strongly Disagree (1).

\begin{tabular}{|c|c|c|c|c|c|c|}
\hline Questions & \multicolumn{6}{|c|}{ Scale } \\
\hline I am able to pass the study and achieved at least a pass mark of 50. & 1 & 2 & 3 & 4 & 5 & 6 \\
\hline I am able to comprehend what I have learned in the class & 1 & 2 & 3 & 4 & 5 & 6 \\
\hline I am able to complete the assigned homework & 1 & 2 & 3 & 4 & 5 & 6 \\
\hline $\begin{array}{l}\text { I am able to meet the performance standard in math, science, social studies, } \\
\text { read and write }\end{array}$ & 1 & 2 & 3 & 4 & 5 & 6 \\
\hline $\begin{array}{l}\text { I have the confidence that I will be able to complete my high school } \\
\text { education }\end{array}$ & 1 & 2 & 3 & 4 & 5 & 6 \\
\hline The teacher asks me questions & 1 & 2 & 3 & 4 & 5 & 6 \\
\hline I work well with other class members & 1 & 2 & 3 & 4 & 5 & 6 \\
\hline I get the same amount of help from the teacher as other students do. & 1 & 2 & 3 & 4 & 5 & 6 \\
\hline I get the same opportunity to answer questions as other students & 1 & 2 & 3 & 4 & 5 & 6 \\
\hline I get the same opportunity to contribute to class discussions as other students. & 1 & 2 & 3 & 4 & 5 & 6 \\
\hline My ideas and suggestions are used during classroom discussions. & 1 & 2 & 3 & 4 & 5 & 6 \\
\hline Members of the class are my friends & 1 & 2 & 3 & 4 & 5 & 6 \\
\hline I have an exciting experience though out my educational endeavor & 1 & 2 & 3 & 4 & 5 & 6 \\
\hline I am looking forward to enter the high school & 1 & 2 & 3 & 4 & 5 & 6 \\
\hline Most of my neighborhood friends are also in the high school & 1 & 2 & 3 & 4 & 5 & 6 \\
\hline My family has a good socioeconomic background & 1 & 2 & 3 & 4 & 5 & 6 \\
\hline Thes & 1 & 2 & 3 & 4 & 5 & 6 \\
\hline The opportunities in this & 1 & 2 & 3 & 4 & 5 & 6 \\
\hline Teachers here are & 1 & 2 & 3 & 4 & 5 & 6 \\
\hline Teachers in this sc & 1 & 2 & 3 & 4 & 5 & 6 \\
\hline Teachers here believe that students are competent learners & 1 & 2 & 3 & 4 & 5 & 6 \\
\hline Teachers & 1 & 2 & 3 & 4 & 5 & 6 \\
\hline $\begin{array}{c}\text { Teachers in my school hold themselves responsible to ensure that all students } \\
\text { succeed }\end{array}$ & 1 & 2 & 3 & 4 & 5 & 6 \\
\hline $\begin{array}{c}\text { Teachers in my school are willing to take responsibility for all students' } \\
\text { learning }\end{array}$ & 1 & 2 & 3 & 4 & 5 & 6 \\
\hline Teachers in my school set high standards for their teaching & 1 & 2 & 3 & 4 & 5 & 6 \\
\hline $\begin{array}{c}\text { Administrative rules in this school are guides to action rather rigid } \\
\text { procedures }\end{array}$ & 1 & 2 & 3 & 4 & 5 & 6 \\
\hline The administrative hierarchy of this school enables teachers to do their jobs & 1 & 2 & 3 & 4 & 5 & 6 \\
\hline $\begin{array}{l}\text { The administrative structures in the facilitates a culture that emphasizes trust, } \\
\text { efficacy, and academics }\end{array}$ & 1 & 2 & 3 & 4 & 5 & 6 \\
\hline
\end{tabular}

\section{Thank you for participating in this survey.}

